Article

\title{
Synthesis and Size Dependent Reflectance Study of Water Soluble SnS Nanoparticles
}

\author{
Ying Xu ${ }^{1}$, Najeh Al-Salim ${ }^{2, *}$ and Richard D. Tilley ${ }^{1, *}$ \\ 1 School of Chemical and Physical Sciences, MacDiarmid Institute of Advance Materials and \\ Nanotechnology, Victoria University of Wellington, P.O. Box 600, Wellington 6011, New Zealand; \\ E-Mail: Sherry.Xu@vuw.ac.nz \\ 2 Industrial Research, Ltd., P.O. Box 31-310, Lower Hutt 5010, New Zealand \\ * Authors to whom correspondence should be addressed; E-Mails: n.al-salim@irl.cri.nz (N.A.-S.); \\ richard.tilley@vuw.ac.nz (R.D.T.); Tel.: +64-4-5690049 (N.A.-S.); +64-4-4635016 (R.D.T.); \\ Fax: +64-4-5690142 (N.A.-S.); +64-4-4635237 (R.D.T.).
}

Received: 21 December 2011; in revised form: 4 January 2012 / Accepted: 5 January 2012 / Published: 16 January 2012

\begin{abstract}
Near-monodispersed water soluble SnS nanoparticles in the diameter range of 3-6 $\mathrm{nm}$ are synthesized by a facile, solution based one-step approach using ethanolamine ligands. The optimal amount of triethanolamine is investigated. The effect of further heat treatment on the size of these $\mathrm{SnS}$ nanoparticles is discussed. Diffuse reflectance study of $\mathrm{SnS}$ nanoparticles agrees with predictions from quantum confinement model.
\end{abstract}

Keywords: tin sulfide; nanoparticles; triethanolamine; water soluble; diffuse reflectance

\section{Introduction}

Semiconductor nanoparticles are of great interest due to their unique size-dependent optical properties and potential applications in various nanoelectronic and optoelectronic devices [1-6]. Interest in the synthesis of group IV-VI semiconductor nanoparticles, such as $\mathrm{PbS}, \mathrm{SnSe}$ and $\mathrm{SnS}$, stems from their narrow band gaps and potential application in photovoltaics, near infrared detectors and biomedical applications [7-12]. These applications have stimulated the development of convenient synthetic methodologies to make monodisperse group IV-VI nanoparticles with narrow size distributions and good size-defined optical properties. 
Unlike cadmium- and lead-containing nanomaterials, tin monosulfide, $\mathrm{SnS}$, is considered to be a less-toxic material. SnS has both direct and indirect band gaps of 1.3 and $1.09 \mathrm{eV}$, respectively, and shows great promise in the field of infrared (IR) photoelectric and thermoelectric devices [13-17]. Various methods, such as solvothermal and hydrothermal, have been utilized to synthesise $\mathrm{SnS}$ nanostructures with different morphologies, such as nanosheets, nanorods [18], nanowires [19] and nanoflowers $[18,20]$. SnS has an orthorhombic layered crystal structure and can hardly grow into a zero-dimensional nanostructure, and therefore, it is a significant challenge to fabricate monodispersed $\mathrm{SnS}$ nanoparticles with a small enough size in a quantum confinement regime.

There are only a few reports that presented synthetic methodologies for forming SnS nanoparticles with a size of less than $10 \mathrm{~nm}$. Hickey and co-workers demonstrated a method of forming $\mathrm{SnS}$ nanoparticles with size around $7 \mathrm{~nm}$, using the air sensitive organometallic complex $\mathrm{Sn}\left[\mathrm{N}\left[\left(\mathrm{SiCH}_{3}\right)_{3}\right]_{2}\right]_{2}$ as a tin precursor, thioacetamide as the sulphur prercursor, and trioctylphosphine (TOP) and oleic acid (OA) as surfactants [21]. More recently, Liu et al. reported the synthesis of around $6 \mathrm{~nm} \mathrm{SnS}$ nanoparticles from $\mathrm{SnCl}_{2}$ and $\left[\left(\mathrm{CH}_{3}\right)_{3} \mathrm{Si}\right]_{2} \mathrm{~S}$ in oleylamine (OLA) [22], and Ning et al. prepared $5 \mathrm{~nm}$ SnS nanoparticles through the reaction of $\left(\mathrm{Sn}_{6} \mathrm{O}_{4}(\mathrm{OH})_{4}\right)$ with thioacetamide in the presence of OA and OLA [23]. However, in these syntheses the products were soluble only in organic solvents, which to some extent limits their use in the biomedical field [24].

In a previous communication [25], we reported a facile, room temperature synthesis to make $\mathrm{SnS}$ nanoparticles of a few nanometers in size. Herein, we report on the full synthetic methods, optical properties and the optimisation of some experimental parameters for the synthesis of SnS nanoparticles in solution using some simple starting materials, $\mathrm{SnBr}_{2}$ and $\mathrm{Na}_{2} \mathrm{~S}$, in the presence of ethanolamines, especially triethanolamine dissolved in ethylene glycol.

\section{Results and Discussion}

\subsection{Synthesis and Properties}

The SnS nanoparticles were synthesised through the reaction of the inorganic starting materials $\mathrm{SnBr}_{2}$ and $\mathrm{Na}_{2} \mathrm{~S}$ in the presence of ethanolamines (EAs) in EG at ambient temperature. The ethanolamine ligands used had either one hydroxyl group (DMEA), two hydroxyl groups (MDEA) or three hydroxyl groups (TEA) (see Scheme 1).

Scheme 1. The chemical structure of DMEA, MDEA and TEA.

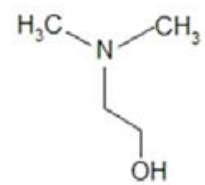

DMEA

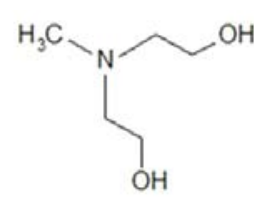

MDEA

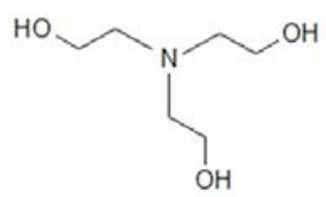

TEA

We have previously shown [25] that the morphology of the EA-stabilized SnS nanoparticles were generally spherical, and in particular, TEA can produce highly monodispersed particles as compared to DMEA and MDEA. These results show that the SnS nanoparticle size and monodispersity can be controlled by the number of hydroxyl groups on the stabilizer. DMEA (one hydroxyl group) produced 
relatively bigger and less monodispersed nanoparticles than MDEA (two hydroxyl groups) which in turn formed bigger and less monodispersed nanoparticles than TEA (three hydroxyl groups). The greater monodispersity with increasing number of hydroxyl groups is more likely due to the ability of multiple hydroxyl groups to bind more strongly to the nanoparticles as they grow.

The bonding of triethanolamine to the surface of the SnS nanoparticles was confirmed by FT-IR spectroscopy (see Figure 1). The spectrum of the nanoparticles showed a significant absorption at $3,365 \mathrm{~cm}^{-1}$ with a shoulder, which are due to the strong $\mathrm{O}-\mathrm{H}$ stretching vibrations and physisorbed and chemisorbed $\mathrm{H}_{2} \mathrm{O}$ [26]. Bands at $2,918 \mathrm{~cm}^{-1}$ and $2,860 \mathrm{~cm}^{-1}$ correspond to the $\mathrm{C}-\mathrm{H}$ stretching vibration. A band at $1,630 \mathrm{~cm}^{-1}$ is due to $\mathrm{H}-\mathrm{O}-\mathrm{H}$ bending of $\mathrm{H}_{2} \mathrm{O}$ molecules. The bands in the region of $1,456-1,210 \mathrm{~cm}^{-1}$ are associated with vibrations of the $\mathrm{C}-\mathrm{C}$ and $\mathrm{C}-\mathrm{H}$ bonds. The $\mathrm{C}-\mathrm{O}$ and $\mathrm{C}-\mathrm{N}$ stretching vibrations were detected at $1,058 \mathrm{~cm}^{-1}$. The band at $898 \mathrm{~cm}^{-1}$ could be due to $\mathrm{C}-\mathrm{N}, \mathrm{C}-\mathrm{C}$, $\mathrm{C}-\mathrm{O}$ and $\mathrm{C}-\mathrm{C}-\mathrm{O}$ vibrations.

Figure 1. FT-IR spectra of (a) neat TEA and (b) TEA-capped SnS nanoparticles prepared at room temperature.

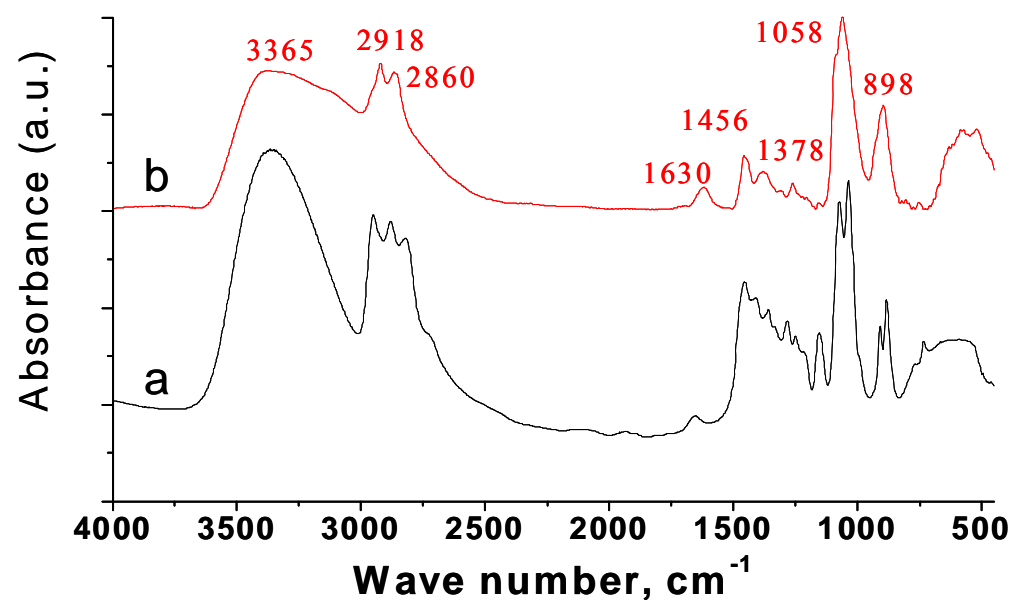

Figure 2. (a) LRHTEM image of $\mathrm{SnS}$ nanoparticles obtained with $6 \mathrm{~mL}$ TEA; (b) Histogram of size distribution of SnS nanoparticles made with $6 \mathrm{~mL}$ TEA.
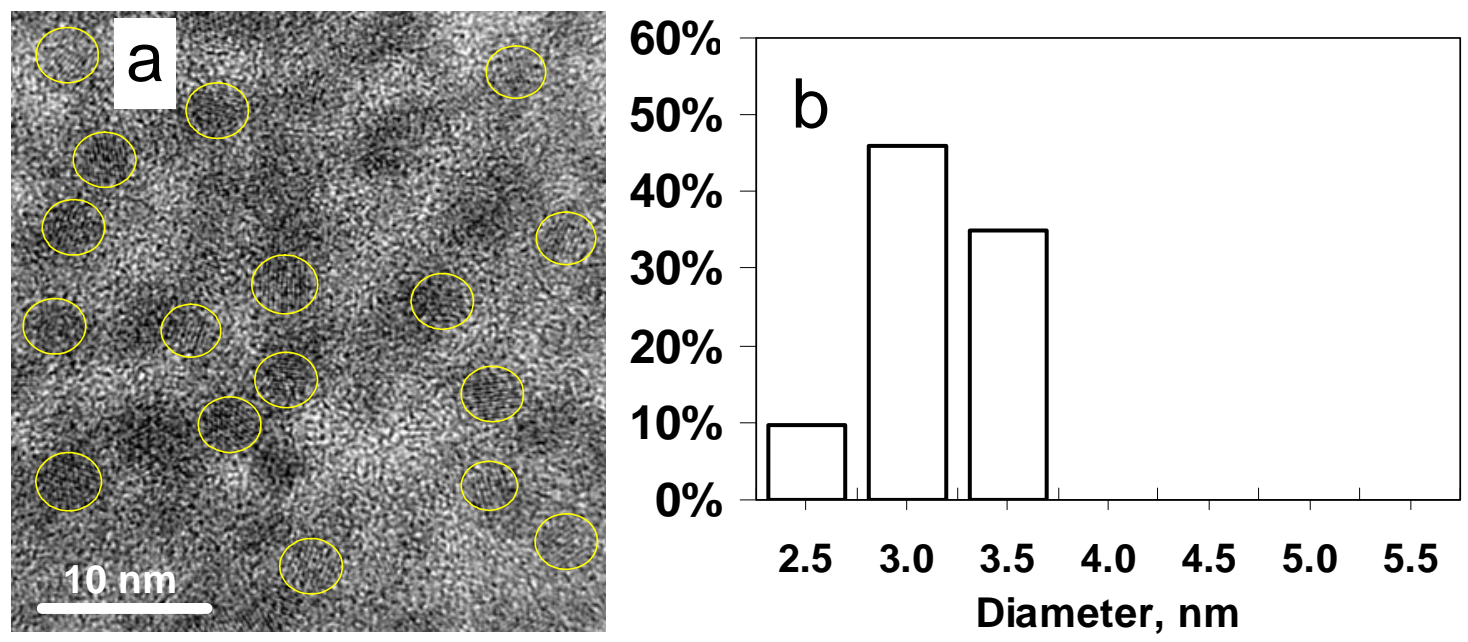

Figure 2a,b shows a TEM image of $3.0 \mathrm{~nm} \mathrm{SnS}$ nanoparticles and the particle size distribution obtained with $6 \mathrm{~mL}$ TEA, respectively. The atomic lattice fringes are clearly observed demonstrating 
the highly crystalline nature of the nanoparticles. A HRTEM image of one $\mathrm{SnS}$ nanocrystal is shown in Figure $3 \mathrm{a}$ and the confirmation of the crystal structure of the TEA stabilised SnS obtained from SAED is shown in Figure 3b. The diffraction rings match well with the orthorhombic crystal structure adopted by $\operatorname{SnS}(\mathrm{Pbnm}, \mathrm{a}=11.143 \AA, \mathrm{b}=3.971 \AA$ and $\mathrm{c}=4.337 \AA)$. The same crystal structure was obtained from MDEA/SnS and DMEA/SnS samples.

Figure 3. (a) HRTEM image of a crystalline $\mathrm{SnS}$ nanoparticle obtained with $6 \mathrm{~mL}$ TEA; (b) Selected area electron diffraction (SAED) pattern of orthorhombic SnS NPs.

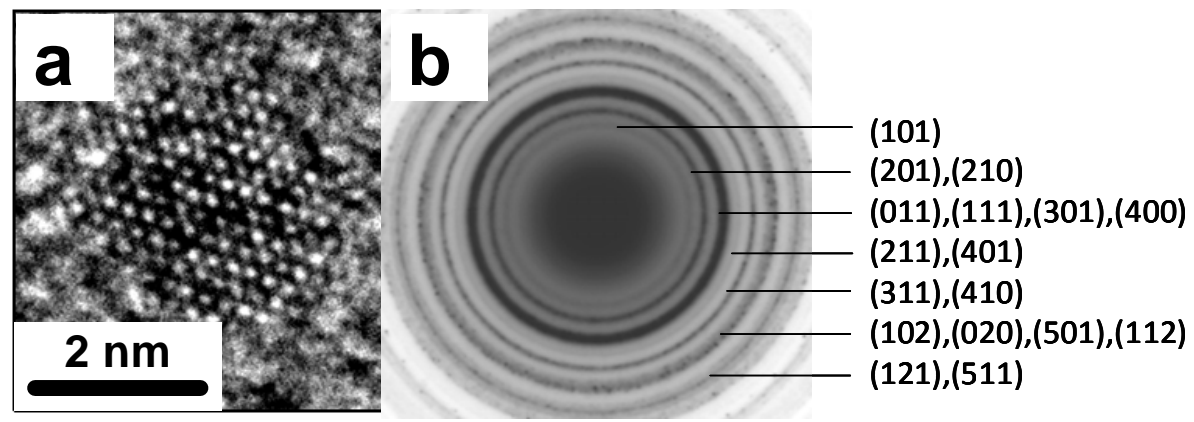

The chemical composition of the as-prepared products using $6 \mathrm{~mL}$ TEA was examined by EDX analysis (Figure 4). The experimental data indicated that the $\mathrm{Sn}: \mathrm{S}$ atomic ratio of $\sim 1: 1$ is consistent with $\mathrm{SnS}$ formula.

Figure 4. Energy dispersion X-ray spectrum (EDX) for SnS nanoparticles prepared in the presence of $6 \mathrm{~mL}$ TEA at room temperature.

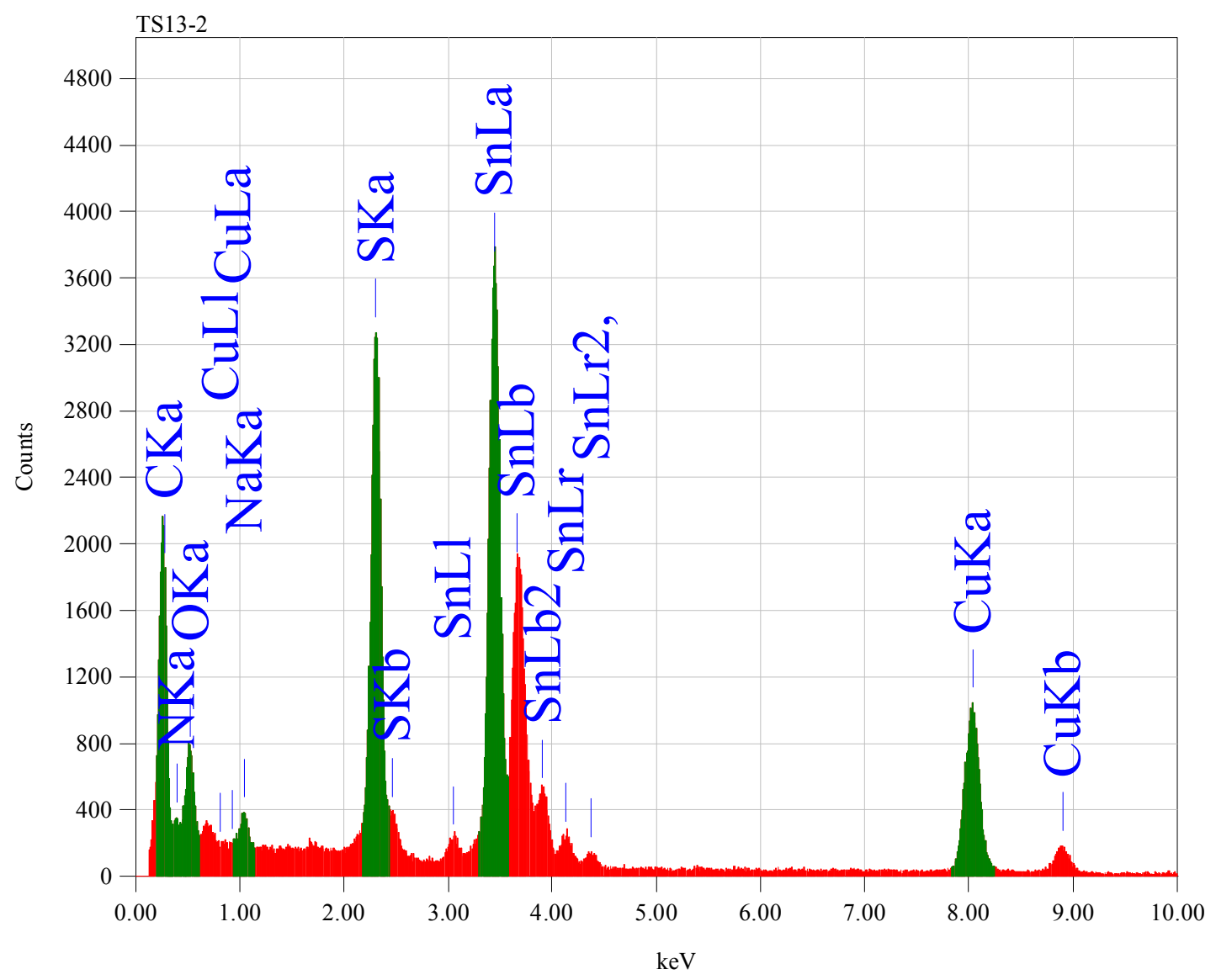




\subsection{Effect of the Amount of TEA}

In our previous work, a general method for making $\mathrm{SnS}$ nanoparticles in the presence of the ethanolamines TEA, MDEA and DMEA was described. Since TEA was found to be the most effective stabiliser among the studied ethanolamines in the formation of SnS nanoparticles, it is important to investigate the optimal amount of TEA required in the reaction. Previous reports showed that TEA can form chelate complexes with $\mathrm{Sn}^{2+}$ having a general formula [Sn(TEA) $]^{2+}$ [27]. In the present reaction system TEA plays a dual role, first as a chelating ligand to the $\mathrm{Sn}^{2+}$ precursor and second as a stabilizer to the so produced SnS NPs. In this study, different TEA amounts $(2,4,6,8$ and $10 \mathrm{~mL})$ were investigated while maintaining other synthetic conditions unchanged. Figure 5a shows a TEM image of the $\mathrm{SnS}$ nanoparticles obtained in the presence of $2 \mathrm{~mL}$ TEA, in which the size of the $\mathrm{SnS}$ nanoparticles is $4.3 \pm 1.0 \mathrm{~nm}$ as shown in Figure $5 \mathrm{~b}$. When $4 \mathrm{~mL}$ TEA was used, the SnS particle size was $3.3 \pm 0.5 \mathrm{~nm}$ (Figure 5c,d). These can be compared with Figure 2a,b which shows the TEM image and the size distribution $(3.0 \pm 0.5 \mathrm{~nm})$ of $\mathrm{SnS}$ nanoparticles respectively obtained in the presence of 6 mL TEA.

Figure 5. TEM images of SnS nanoparticles synthesized in the presence of (a) $2 \mathrm{~mL}$ TEA; and (c) $4 \mathrm{~mL}$ TEA at room temperature, respectively. Histograms of particle size distribution for (b) $\mathrm{SnS}$ nanoparticles made with $2 \mathrm{~mL}$ TEA; and (d) $\mathrm{SnS}$ nanoparticles made with $4 \mathrm{~mL}$ TEA.
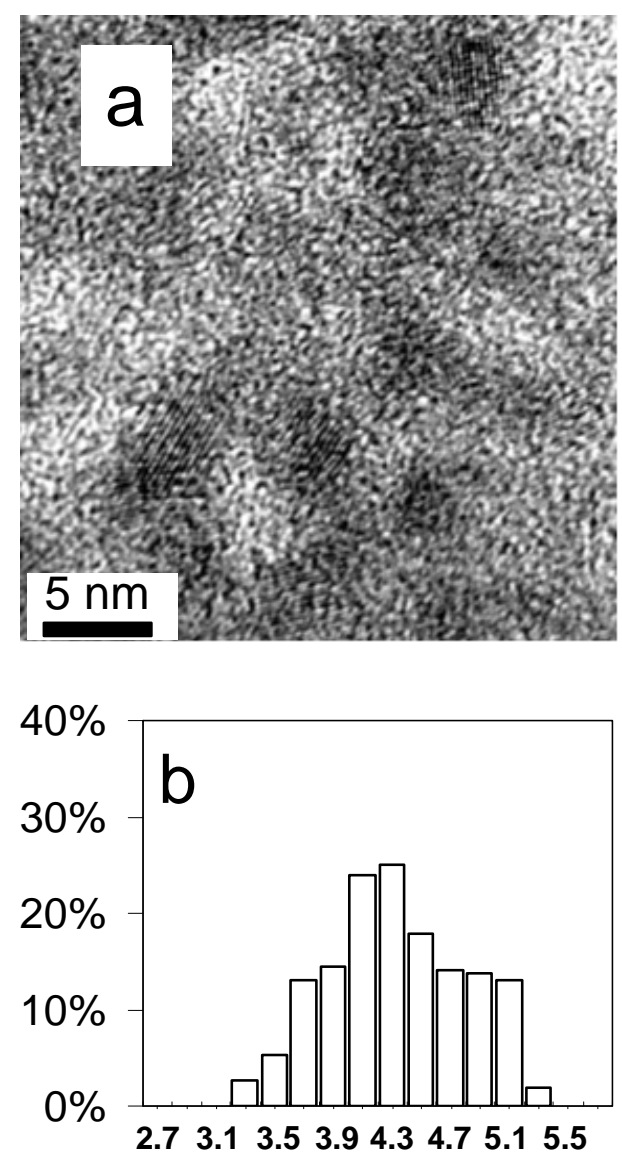

Diameter, $\mathrm{nm}$
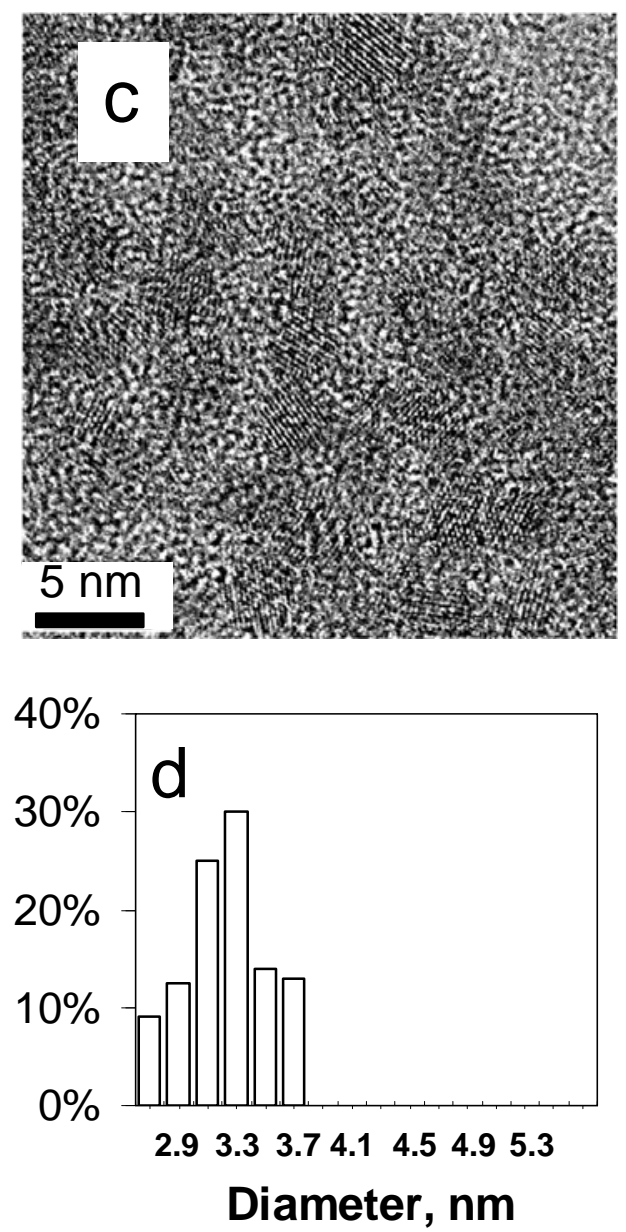
From the above data one can see that using $2 \mathrm{~mL}$ TEA gave slightly bigger and broader size distribution nanoparticles $(4.3 \pm 1.0 \mathrm{~nm})$ than using $4 \mathrm{~mL}$ TEA $(3.3 \pm 0.5 \mathrm{~nm})$ which in turn formed slightly bigger nanoparticles than using $6 \mathrm{~mL}$ TEA $(3.0 \pm 0.5 \mathrm{~nm})$. Therefore, the size of $\operatorname{SnS}$ nanoparticles can be controlled by the amount of the stabilizing TEA ligand, such that the size of the nanoparticles decreased with increasing the TEA amount in the reaction system. Addition of TEA can control the growth of the SnS nuclei and form nearly uniform particles. It was noticed that using $8 \mathrm{~mL}$ TEA or more tended to highly stabilise the $\mathrm{Sn}^{2+}$ precursor complex, and therefore, slowed down the formation of SnS nanoparticles and gave less yield under the same conditions. Based on these results, $6 \mathrm{~mL}$ TEA per $0.2 \mathrm{mmol}$ of $\mathrm{SnBr}_{2}$ could be considered as the optimum amount of this stabiliser for the synthesis of small and monodispersed $\mathrm{SnS}$ nanoparticles under the so used experimental conditions.

Figure 6 and the inset therein show the reflectance spectra of $\mathrm{SnS}$ nanoparticle of sizes 4.3, 3.3 and $3.0 \mathrm{~nm}$ prepared in the presence of $2 \mathrm{~mL}, 4 \mathrm{~mL}$ and $6 \mathrm{~mL}$ of TEA respectively [28]. The particles that were produced using $6 \mathrm{~mL}$ TEA showed a reflectivity edge at $1.76 \mathrm{eV}$. The larger nanoparticles produced using $4 \mathrm{~mL}$ and $2 \mathrm{~mL}$ TEA showed reflectivity edges that are red-shifted by $\sim 0.1 \mathrm{eV}$ and $\sim 0.2 \mathrm{eV}$, respectively, compared to that of the SnS nanoparticles prepared using $6 \mathrm{~mL}$ TEA. The red shift of the reflectivity edge with increasing the nanoparticle size could be attributed to the quantum confinement effect.

Figure 6. Reflectance spectra (normalised) of films that cast from different size nanoparticles made in the presence of 2, 4 and $6 \mathrm{~mL}$ TEA. Inset: The first derivative of film reflectance versus incident photon energy.

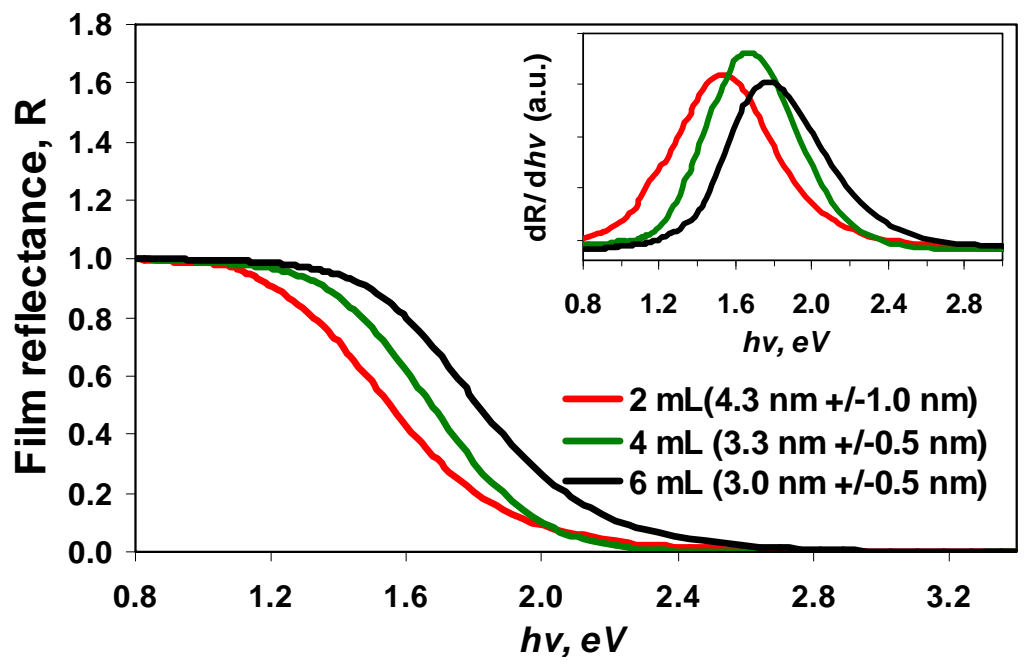

\subsection{Effect of Heat Treatment}

Previous research has shown that the average particle size and crystallinity of nanoparticles can be increased by either heat treatment at elevated temperature or longer time heating [29-31]. So, the effect of heat treatment on the properties of $\mathrm{SnS}$ nanoparticles is investigated here. SnS nanoparticles were first prepared at room temperature in the presence of $6 \mathrm{~mL}$ TEA, followed by further heating to $100{ }^{\circ} \mathrm{C}$ for 10,30 , and $60 \mathrm{~min}$. TEM images showed that before heat treatment, the particles had predominantly spherical shape with an average size of $3.0 \pm 0.5 \mathrm{~nm}$, as shown in Figure 2a. After heat treatment, the particles became predominantly oval or have irregular shape with an increase in the 
average particle size depending on the heat treatment time (Figure 7). When the nanoparticles were heated for 10 minutes, the average size of the nanoparticles was $4.0 \pm 1.0 \mathrm{~nm}$. After heat treatment for 30 minutes, the nanoparticles grew to an average size of $5.1 \pm 1.5 \mathrm{~nm}$. By extending the heat treatment time to 60 minutes, the average size of the $\mathrm{SnS}$ nanoparticles reached to $6.0 \pm 1.5 \mathrm{~nm}$. The increase in the particle size may be explained by Ostwald ripening mechanism due to the heat treatment [32].

Figure 7. TEM images of $\mathrm{SnS}$ nanoparticles synthesized using $6 \mathrm{~mL}$ TEA at room temperature with further heat treatment at $100{ }^{\circ} \mathrm{C}$ for (a) $10 \mathrm{~min}$, (b) $30 \mathrm{~min}$, and (c) $60 \mathrm{~min}$, respectively. The corresponding histograms of the size distribution for the $\mathrm{SnS}$ nanoparticles are shown in (d) $10 \mathrm{~min}$, (e) $30 \mathrm{~min}$, and (f) $60 \mathrm{~min}$.
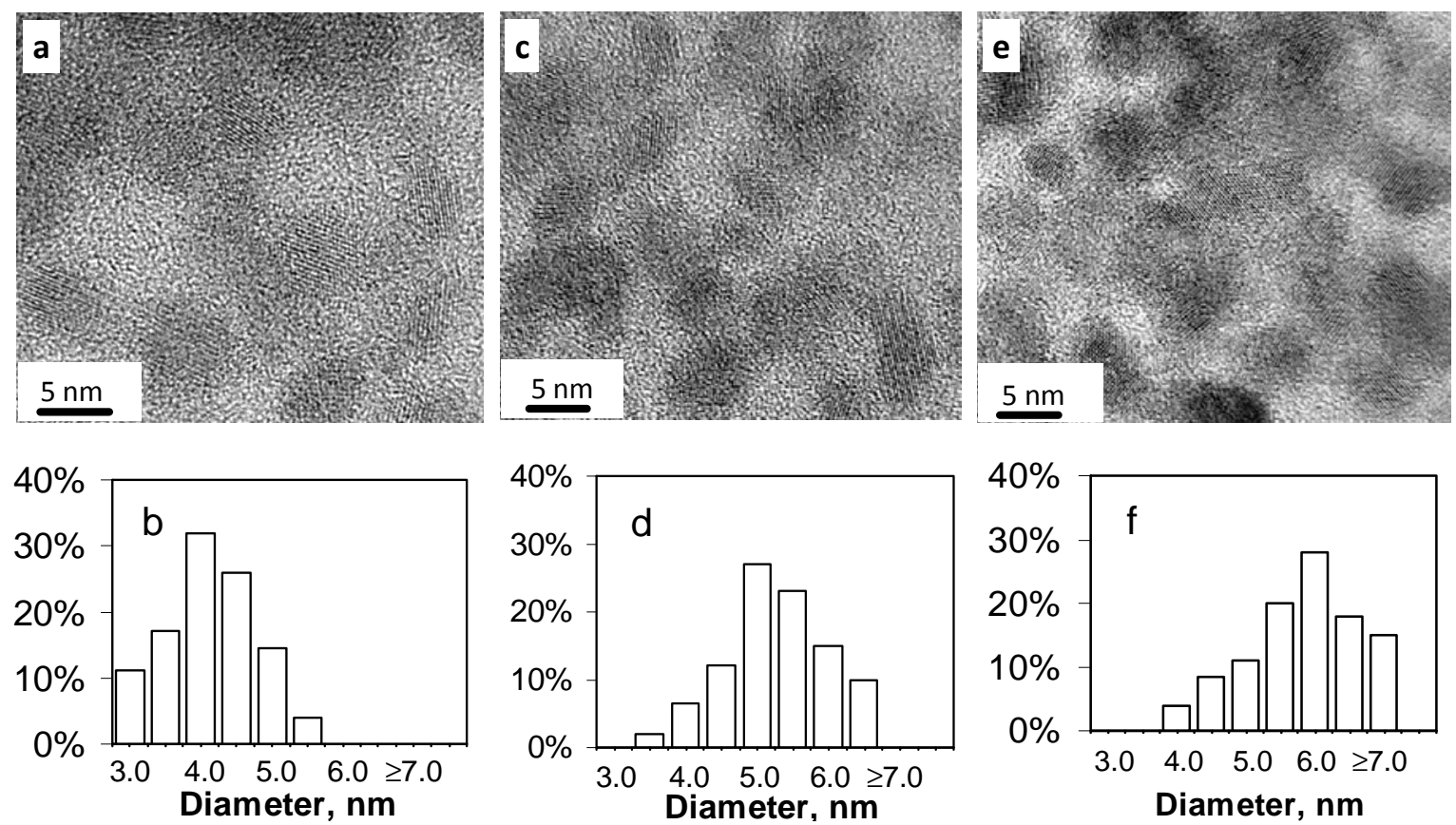

Figure 8. Reflectance spectra (normalised) of $\mathrm{SnS}$ nanoparticle films that cast from particles made in the presence of $6 \mathrm{~mL}$ TEA at different heating time. Inset: The first derivative of film reflectance versus incident photon energy.

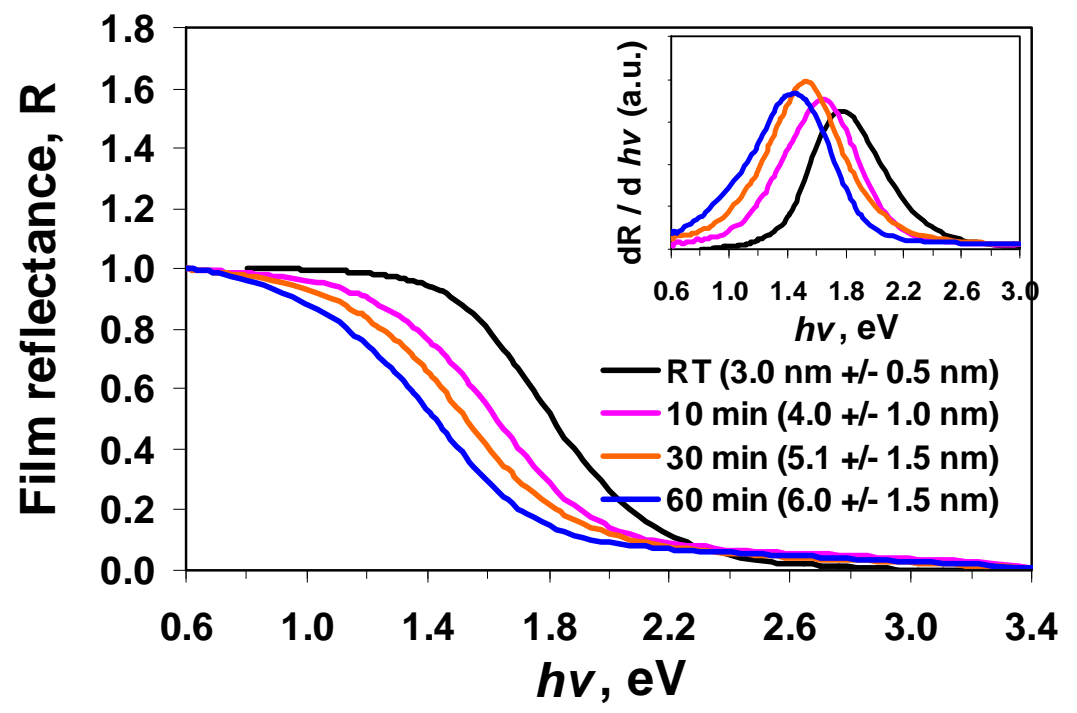


Figure 8 shows the diffuse reflectance spectra of the samples prepared with and without heat treatment. It can be seen from the derivative graphs in the inset that the reflectivity edge red-shifted from 1.76 to $1.45 \mathrm{eV}$ by increasing the heat treatment time from 0 to $60 \mathrm{~min}$. These results are significant as they illustrate the ability to control nanoparticle size in the quantum confinement regime leading to $\mathrm{SnS}$ nanoparticles exhibiting tunable optical properties. The inset in Figure 8 shows that the shape of the reflectivity derivative curves became broader after the particles were heated, which could be due to a wider size population caused by heating.

\section{Experimental Section}

\subsection{Materials}

All syntheses were performed under Argon. Tin(II) bromide ( $\mathrm{SnBr}_{2}$, anhydrous, 99.99\%), sodium sulphide $\left(\mathrm{Na}_{2} \mathrm{~S}, 98 \%\right)$ and ethylene glycol $(\mathrm{EG}, \geq 99 \%)$ were purchased from Aldrich. Triethanolamine (TEA) was purchased from Pure Science. N-methyldiethanolamine (MDEA) and $N, N$-dimethylethanolamine (DMEA, 99\%) were purchased from ACROS. All the chemicals were used as received without further purification. A $0.1 \mathrm{M} \mathrm{Na}_{2} \mathrm{~S}$ solution was prepared by stirring an appropriate amount of $\mathrm{Na}_{2} \mathrm{~S}$ in $\mathrm{EG}$ for $1 \mathrm{~h}$ at room temperature in an Argon atmosphere.

\subsection{A Typical Synthesis of SnS Nanoparticles in the Presence of Triethanolamine}

$\mathrm{SnBr}_{2}(0.056 \mathrm{~g}, 0.2 \mathrm{mmol})$ was dissolved in a mixture of $20 \mathrm{~mL}$ EG and 2, 4, 6, 8 or $10 \mathrm{~mL}$ TEA with vigorous stirring at room temperature under Argon flow. $2 \mathrm{~mL}$ of $0.1 \mathrm{M}$ solution of $\mathrm{Na}_{2} \mathrm{~S}$ in EG was added drop-wise over $10 \mathrm{~min}$ into the vigorously stirred $\mathrm{SnBr}_{2}$ solution. The resulting brown-coloured $\mathrm{SnS}$ nanoparticles were separated via centrifugation (50,000 rpm for $1-2 \mathrm{~h})$ and washed repeatedly in ethanol for four times and stored in a desired solvent for subsequent morphology and optical properties measurement. A similar method was used to prepare MDEA and DMEA-tagged SnS NPs.

\subsection{Heat Treatment}

The synthesis was first carried out at room temperature in the presence of $6 \mathrm{~mL}$ TEA followed by heating at $100{ }^{\circ} \mathrm{C}$ for 10,30 or $60 \mathrm{~min}$.

\subsection{Characterization Methods}

Transmission Electron Microscopy (TEM), selected area electron diffraction (SAED) and energy dispersion X-ray spectroscopy (EDX) were recorded by a JEOL 2010 electron microscopy with an accelerating voltage of $200 \mathrm{kV}$. Samples were prepared by placing a drop of dilute, well dispersed colloidal solution onto a 200-mesh amorphous carbon-coated copper TEM grid purchased from ProSciTech. The software Gatan Digital Micrograph was used to capture and process images. Particle size distribution analyses were based on 120-150 nanoparticles. 
Diffuse reflectance spectra were recorded on a High Accuracy Reference Spectrophotometer at IRL [26] in the wavelength range from $250 \mathrm{~nm}$ to $2,500 \mathrm{~nm}$. The reflectivity measurements were made on drop-cast films of as-prepared nanoparticles deposited on glass substrates.

Fourier Transform Infrared (FT-IR) spectra were recorded using PerkinElmer Spectrum One FT-IR spectrometer with wave number range of 4,000-400 $\mathrm{cm}^{-1}$. Pellets for FT-IR measurement were prepared by mixing the dried samples (after purification) with spectroscopic grade $\mathrm{KBr}$ powder. Equal mass of $\mathrm{KBr}$ was used as a reference.

\section{Conclusions}

The synthesis of monodispersed colloidal SnS nanoparticles with sizes of a few nanometers were successfully demonstrated using ethanolamine ligands. The results show that ethanolamines, particularly TEA, are a class of ligands that can be used as stabilisers for $\mathrm{SnS}$ nanoparticles and other metal chalcogenide nanoparticles, such as SnTe [33].

The size of the resulting $\mathrm{SnS}$ nanoparticles can be tuned by changing the reaction parameters. Surfactants were shown to be the key factor in the size control of SnS nanoparticles. Due to the higher chelating effect of the three hydroxyl groups, TEA molecule proved to give the best particle size control compared to MDEA and DMEA. The optimal amount of TEA in the reaction system has been investigated. Heat treatment of the nanoparticles led to an increase in the particle size. Diffuse reflectance study of the $\mathrm{SnS}$ nanoparticles showed a size dependent effect on the reflectivity which may due to the quantum confinement. These results further unlock the potential of SnS materials for photocatalysts and solid state batteries [34-38].

\section{Acknowledgments}

Y.X., N.A. and R.D.T. thank MSI for funding through grant IIOF VICX0601. R.D.T. thanks the MacDiarmid Institute and MSI for funding through grant PROJ-13733-NMTS. The authors would like to thank J. Hamlin (IRL) for the diffuse reflectance measurements.

\section{References and Notes}

1. Alivisatos, A.P. Semiconductor clusters, nanocrystals, and quantum dots. Science 1996, 271, 933-937.

2. Talapin, D.V.; Lee, J.-S.; Kovalenko M.V.; Shevchenko, E.V. Prospects of colloidal nanocrystals for electronic and optoelectronic applications. Chem. Rev. 2010, 110, 389-458.

3. Leitsmann R.; Bechstedt, F. Characteristic energies and shifts in optical spectra of colloidal IV-VI semiconductor nanocrystals. ACS Nano 2009, 3, 3505-3512.

4. Schaller, R.D.; Sykora, M.; Jeong, S.; Klimov, V.I. High-efficiency carrier multiplication and ultrafast charge separation in semiconductor nanocrystals studied via time-resolved photoluminescence. J. Phys. Chem. B 2006, 110, 25332-25338.

5. Willander, M.; Yang, L.L.; Wadeasa, A.; Ali, S.U.; Asif, M.H.; Zhao, Q.X.; Nur, O. Zinc oxide nanowires: Controlled low temperature growth and some electrochemical and optical nano-devices. J. Mater. Chem. 2009, 19, 1006-1018. 
6. Zhou, W.J.; Liu, X.Y.; Cui, J.J.; Liu, D.; Li, J.; Jiang, H.D.; Wang, J.Y.; Liu, H. Control synthesis of rutile $\mathrm{TiO}_{2}$ microspheres, nanoflowers, nanotrees and nanobelts via acid-hydrothermal method and their optical properties. Cryst. Eng. Comm. 2011, 13, 4557-4563.

7. Antunez, P.D.; Buckley, J.J.; Brutchey, R.L. Tin and germanium monochalcogenide IV-VI semiconductor nanocrystals for use in solar cells. Nanoscale 2011, 3, 2399-2411.

8. Jain, P.K.; Amirav, L.; Aloni, S.; Alivisatos, A.P. Nanoheterostructure cation exchange: Anionic framework conservation. J. Am. Chem. Soc. 2010, 132, 9997-9999.

9. Lee, J.-S.; Shevchenko, E.V.; Talapin, D.V. Au-PbS core-shell nanocrystals: Plasmonic absorption enhancement and electrical doping via intra-particle charge transfer. J. Am. Chem. Soc. 2008, 130, 9673-9675.

10. Franzman, M.A.; Schlenker, C.W.; Thompson, M.E.; Brutchey, R.L. Solution-phase synthesis of SnSe nanocrystals for use in solar cells. J. Am. Chem. Soc. 2010, 132, 4060-4061.

11. Baumgardner, W.J.; Choi, J.J.; Hanrath, T. SnSe nanocrystals: Synthesis, structure, optical properties, and surface chemistry. J. Am. Chem. Soc. 2010, 132, 9519-9521.

12. Greyson, E.C.; Barton, J.E.; Odom, T.W. Tetrahedral zinc blende tin sulfide nano- and microcrystals. Small 2006, 2, 368-371.

13. Zainal, Z.; Hussein M.Z.; Ghazali, A. Cathodic electrodeposition of $\mathrm{SnS}$ thin films from aqueous solution. Sol. Energy Mater. Sol. Cells 1996, 40, 347-357.

14. Parenteau, M.; Carlone, C. Influence of temperature and pressure on the electronic transitions in SnS and SnSe semiconductors. Phys. Rev. B 1990, 41, 5227-5234.

15. Koteswara Reddy, N.; Ramakrishna Reddy, K.T. Growth of polycrystalline SnS films by spray pyrolysis. Thin Solid Films 1998, 325, 4-6.

16. Tanusevski, A.; Poelman, D. Optical and photoconductive properties of $\mathrm{SnS}$ thin films prepared by electron beam evaporation. Sol. Energy Mater. Sol. Cells 2003, 80, 297-303.

17. Wang, Y.; Gong, H.; Fan, B.H.; Hu, G.X. Photovoltaic behavior of nanocrystalline $\mathrm{SnS} / \mathrm{TiO}_{2}$. J. Phys. Chem. C 2010, 114, 3256-3259.

18. Panda, S.K.; Gorai, S.; Chaudhuri, S. Shape selective solvothermal synthesis of SnS: Role of ethylenediamine-water solvent system. Mater. Sci. Eng. B 2006, 129, 265-269.

19. Hu, H.; Yang, B.; Zeng, J.; Qian, Y. Morphology evolution of SnS nanocrystals: From 3D urchin-like architectures to 1D nanostructures. Mater. Chem. Phys. 2004, 86, 233-237.

20. Zhu, H.; Yang, D.; Zhang, H.; Hydrothermal synthesis, characterization and properties of SnS nanoflowers. Mater. Lett. 2006, 60, 2686-2689.

21. Hickey, S.G.; Waurisch, C.; Rellinghaus, B.; Eychmüller, A. Size and shape control of colloidally synthesized IV-VI nanoparticulate tin(II) sulfide. J. Am. Chem. Soc. 2008, 130, 14978-14980.

22. Liu, H.; Liu, Y.; Wang Z.; He, P. Facile synthesis of monodisperse, size-tunable SnS nanoparticles potentially for solar cell energy conversion. Nanotechnology 2010, 21, 105707.

23. Ning, J.; Men, K.; Xiao, G.; Wang, L.; Dai, Q.; Zou, B.; Liu, B.; Zou, G. Facile synthesis of IV-VI SnS nanocrystals with shape and size control: Nanoparticles, nanoflowers and amorphous nanosheets. Nanoscale 2010, 2, 1699-1703.

24. De, M.; Ghosh, P.S.; Rotello, V.M. Applications of nanoparticles in biology. Adv. Mater. 2008, 20, 4225-4241. 
25. Xu, Y.; Al-Salim, N.; Bumby, C.W.; Tilley, R.D. Synthesis of SnS quantum dots. J. Am. Chem. Soc. 2009, 131, 15990-15991.

26. Jiang, T.; Ozin, G.A.; Verma A.; Bedard, R.L. Adsorption and sensing properties of microporous layered tin sulfide materials. J. Mater. Chem. 1998, 8, 1649-1656.

27. P.; Basu, P.K.; Biswas, S. Preparation and characterization of chemically deposited tin(II) sulphide thin films. Thin Solid Films 1987, 150, 269-276.

28. Diffuse reflectance spectra were record on a High Accuracy Reference Spectrophotometer at the measurement standards laboratory of New Zealand (MSL)/Industrial Research Limited.

29. Yang, W.; Gao, F.; Wei G.; An, L. Ostwald ripening growth of silicon nitride nanoplates. Cryst. Growth Des. 2010, 10, 29-31.

30. Tonti, D.; Mohammed, M.B.; Al-Salman, A.; Pattison, P.; Chergui, M. Multimodal distribution of quantum confinement in ripened CdSe nanocrystals. Chem. Mater. 2008, 20, 1331-1339.

31. Zhong, X.; Feng, Y.; Zhang, Y. Facile and reproducible synthesis of red-emitting CdSe nanocrystals in amine with long-term fixation of particle size and size distribution. J. Phys. Chem. C 2007, 111, 526-531.

32. Rimer, J.D.; Trofymluk, O.; Navrotsky, A.; Lobo, R.F.; Vlachos, D.G. Kinetic and thermodynamic studies of silica nanoparticle dissolution. Chem. Mater. 2007, 19, 4189-4197.

33. Xu, Y.; Al-Salim, N.; Hodgkiss, J.M.; Tilley, R.D. Solution synthesis and optical properties of SnTe nanocrystals. Cryst. Growth Des. 2011, 11, 2721-2723.

34. Tang, P.; Chen, H.; Cao, F.; Pan, G.; Wang, K.; Xu, M.; Tong, Y. Nanoparticulate SnS as an efficient photocatalyst under visible-light irradiation. Mater. Lett. 2011, 65, 450-452.

35. Gao, C.; Shen, H.; Sun, L.; Shen, Z. Chemical bath deposition of SnS films with different crystal structures. Mater. Lett. 2011, 65, 1413-1415.

36. Sohila, S.; Rajalakshmi, M.; Muthamizhchelvan, C.; Kalavathi, S.; Ghosh, C.; Divakar, R.; Venkiteswaran, C.N.; Muralidharan, N.G.; Arora, A.K.; Mohandas, E. Synthesis and characterization of $\mathrm{SnS}$ nanosheets through simple chemical route. Mater. Lett. 2011, 65, 1148-1150.

37. Koteeswara Reddy, N.; Devika, M.; Ahsanulhaq, Q.; Gunasekhar, K.R. Growth of orthorhombic SnS nanobox structures on seeded substrates. Cryst. Growth Des. 2010, 10, 4769-4772.

38. Aso, K.; Hayashi, A.; Tatsumisago, M. Synthesis of needlelike and platelike SnS active materials in high-boiling solvents and their application to all-solid-state lithium secondary batteries. Cryst. Growth Des. 2011, 11, 3900-3904.

(C) 2012 by the authors; licensee MDPI, Basel, Switzerland. This article is an open access article distributed under the terms and conditions of the Creative Commons Attribution license (http://creativecommons.org/licenses/by/3.0/). 